\title{
Patterns of phenotypic variation in endod (Phytolacca dodecandra) from Ethiopia
}

\author{
KASSA SEMAGN ${ }^{1 *}$, BRITA STEDJE ${ }^{2}$ AND ASMUND BJORNSTAD ${ }^{1}$ \\ ${ }^{1}$ Agricultural University of Norway, Department of Plant and Environmental Sciences, P. O. Box 5003, N-1432, Ås, \\ Norway. \\ ${ }^{2}$ University of Oslo, Botanical Garden, P. O. Box 1172, Blindern, N-0318, Oslo, Norway.
}

Accepted 4 December 2003

\begin{abstract}
The extent of morphological variability of endod (Phytolacca dodecandra) sampled from 17 localities in Ethiopia that varied from 1600 to 3000 meters above sea level (m.a.s.l) was investigated using 16 characters. Statistical analyses were performed using leaf hairiness and altitude as categorical variables. Cluster analysis performed using average taxonomic distance matrix revealed the separation of most plants into their respective leaf hairiness and altitude groups. When leaf hairiness was used as categorical variable, canonical discriminant analysis performed using characters selected by the stepwise procedure revealed the distinct separation of all glabrous plants from the pubescent ones with the slightly pubescent plants being intermediate. Classificatory discriminant analysis was used to assign $95.8 \%$ of the plants into their respective hairiness groups. Our data therefore support the hypothesis that pubescent forms are highly likely to be a different taxon. For altitude groups, canonical discriminant analysis performed using characters selected by the stepwise procedure resulted to the separation of most plants into lowland (1600-2100 m.a.s.I.), central highlands (2101-2500 m.a.s.I.), and highland (2501-3000 m.a.s.I) groups. Classificatory discriminant analysis was able to assign $70.8 \%$ of the plants into their respective altitude groups. However, all results from discriminant analyses of the morphological data were not strong enough to support the presence of morphological ecotypes in endod along altitudinal gradients.
\end{abstract}

Key words: Altitude, endod, morphological variation, Phytolacca dodecandra, pubescence.

\section{INTRODUCTION}

Endod (Phytolacca dodecandra L'Herit) is distributed in Sub-Saharan Africa, South America, and Asia (Dalziel, 1936). In Ethiopia, the species is naturally found at altitudes that range between 1600 and 3000 meters above sea level (m.a.s.l.) (Wolde-Yohannes, 1983). Endod has often glabrous but less commonly pubescent leaves and racemes, short pedunculate racemes with several flowers, and bluntly star-shaped berries (Polhill, 1971). The berries of endod synthesize various triterpenoid saponins, which possess potent and useful biological properties including detergent, molluscicidal (Lemma, 1965, 1970; Parkhurst et al., 1974; Lemma et al.,

\footnotetext{
${ }^{*}$ Corresponding author. Fax: $\begin{array}{lllllll}47 & 64 & 94 & 78 & 02 . & \text { E-mail: }\end{array}$
} kassa.semagn@ipm.nlh.no.
1991), spermicidal (Stolzenberg and Parkhurst, 1976), insecticidal (Spielman and Lemma, 1973), and fungicidal (Abate and Fesseha, 1994) properties. Most scientifically studied use of endod is its molluscicidal property: it kills the intermediate host snails that harbor schistosomes that cause the disease schistosomiasis or bilharzia. In contrast to all other currently available molluscicides, endod berries will have dual purposes: as soap for washing clothes and as molluscicide for killing schistosome transmitting snails. The use of endod for schistosomiasis control is considered cheaper, environmentally safe, biodegradable and more readily available plant molluscicide than the currently available synthetic chemicals (Kloos and McCullough, 1983; Lambert et al., 1991; Molgaard et al., 2000).

At present, Ethio-Coffee and Tea Plantation and Marketing is the only company that started large scale 
cultivation of one selected endod clone (E44) for commercial purposes. However, E44 has been found susceptible to insects, nematodes and fungi. On the other hand, other endod types with hairy structures on leaves and stems were not found attractive for oviposition and hence considered to be resistant to Gitona attack (Lugt, 1981). Hence, breeding may be necessary to develop clones, which are more resistant to pests and diseases, and have a better adaptation to the lowland conditions of the country.

Studies on the morphological variation of endod from herbarium specimens collected from different parts of Africa revealed a major regional differentiation of the species into East and West Africa, with clear separation of pubescent plants from Ethiopia (Adams et al., 1989). That study, however, did not attempt to assess if there is clear difference between glabrous and pubescent plants within Ethiopia. Semagn et al. $(2000,2001)$ have previously used random amplified polymorphic DNA (RAPD) analysis to investigate the genetic diversity and structure of 17 Ethiopian endod populations sampled along altitudinal gradients that varied from 16000 to 3000 meters above sea level (m.a.s.l.). That study demonstrated the presence of clear genetic differentiation of the populations into two or three altitude groups: (a) cluster analysis revealed distinct differentiation of the lowland (1600-2100) and central highland (2101-2500) plants from those of the highlands $(2501-3000 \mathrm{~m}$; Semagn et al., 2001); (b) canonical discriminant analysis separated the lowland plants from the highlands with the central highland plants being intermediate between the former (Semagn et al., 2000). The separation of populations into lowland and/or central-highland and highland groups was independent of their geographical origin and climatic zones. Based on the molecular data, therefore, we have previously proposed that the lowland and highland altitude groups may be different ecotypes and/or different in ploidy level (Semagn et al., 2000).

The ploidy level of endod is unclear. Chromosome counts made from Rwanda plant material indicated that the species is tetraploid with $2 n=4 x=36$ (Auquier and Renard, 1975), while preliminary chromosome counts from Ethiopian material indicated a much higher ploidy level (B. Stedje and K. Dagne, unpublished) although detailed investigation was found to be difficult due to the small size of chromosomes $(<1 \mu \mathrm{m})$. Stomatal size (guard cell length), stomatal frequency, and stomatal plastid number have been used as morphological markers for identifying ploidy levels in several plant species, including Lolium perenne (Speckman et al., 1965), Bromus inermis (Tan and Dun, 1973), Dactylis spp. (Santen and Casler, 1986) and Coffea spp. (Mishra, 1997). In endod, stomatal size was measured from 48 samples to determine if the data could be used to predict differences in ploidy level between altitude groups. These preliminary data, however, did not indicate any significant difference between altitude groups (B. Stedje, unpublished). An alternative method of testing differences in ploidy level is to cross the lowland and highland genotypes and assess the viability and seed set of F1 plants, which is currently in progress. The objectives of this study were therefore to test the hypotheses that (1) pubescent forms constitute a separate taxon, and (2) the observed molecular groups along altitudinal gradients could be morphological ecotypes.

\section{MATERIALS AND METHODS}

A total of 48 herbarium specimens were collected from 17 localities in Ethiopia (Figure 1; Table 1). The full range of eco-geographical variation encountered in the species was represented. Each specimen was scored for 16 morphological characters, 13 of which were quantitative and 3 were qualitative (Table 2). The specimens were classified into three leaf hairiness groups based on the level of hairs present on leaves: glabrous (leaves with no hairs), slightly pubescent (leaves with scattered hairs), and pubescent (leaves with dense hairs). The specimens were also classified into lowland (1600-2100 m.a.s.I.), central highland (2101-2500 m.a.s.I.), and highland (2501-3000 m.a.s.l.) altitude groups in the same way as reported in our previous paper (Semagn et al., 2001). Except for Bure, five years (1992-96) temperature and rainfall data were obtained from Ethiopian Meteorological Service Agency in Addis Ababa. All data were standardized prior to statistical analyses.

Four different statistical methods were used. (1) Pearson correlation coefficients were calculated to test for association between pairs of morphological characters and between morphological characters and sampling site data (altitude, average temperature and annual rainfall). (2) Differences for morphological characters among groups were analyzed by performing separate one-way analysis of variance (ANOVA) with Duncan's multiple tests for pair wise comparison of means between groups. (3) Average taxonomic distance matrix was computed and used to generate phenograms using UPGMA method of SAHN clustering (Rohlf, 1998). (4) Different discriminant analyses were used to summarize variation between predefined hairiness and altitude groups. Stepwise discriminant analysis was performed to select an optimal set of discriminating variables (morphological characters) that tended to separate the groups to a maximum degree. Variables were chosen to enter or leave the discrimination model among groups based on the significance level of an $F$ test $(p=0.15)$ from analysis of covariance, where the variables already chosen act as covariates and variables under consideration is the dependent variable. Canonical discriminant analysis was used to summarize variation between groups, based on the morphological characters chosen by the stepwise procedure. Classificatory discriminant analysis with cross validation was used for correct classification of plants into their respective groups. Correlation, ANOVA, and discriminant analyses were performed using SPSS for windows, version 8.0.

\section{RESULTS AND DISCUSSION}

\section{Correlation analysis}

The matrix of correlation coefficients highlighted associations between some pairs of morphological characters and between some morphological characters and sampling site data (Table 3). High positive correlations were obtained between leaf length and leaf 
Table 1. Some collection passport data of endod from 17 localities in Ethiopia.

\begin{tabular}{lllclc}
\hline Locality code & Locality name & Geographical region & Altitude $(\mathbf{m})$ & Altitude group & Sample size \\
\hline 1 & Wondo Genet & Sidamo & 1900 & Lowland & 6 \\
2 & Kofele & Arsi & 2700 & Highland & 2 \\
3 & Mt. Zuquala & Shewa & 2900 & Highland & 4 \\
4 & Menagesha & Shewa & 2400 & Central highland & 7 \\
5 & Debre Sina & Shewa & 2800 & Highland & 2 \\
6 & Dese & Welo & 2500 & Central highland & 3 \\
7 & Korem & Welo & 2450 & Central highland & 3 \\
9 & Woken & Gonder & 2700 & Highland & 2 \\
10 & Taragedam & Gonder & 2300 & Central highland & 2 \\
11 & Bure & Gojam & 2100 & Lowland & 3 \\
12 & Dima & Welega & 2000 & Lowland & 2 \\
13 & Nugema & Welega & 1800 & Lowland & 2 \\
14 & Gechi & llubabor & 1600 & Lowland & 2 \\
15 & Gina & llubabor & 2400 & Central highland & 2 \\
19 & Gerima & Kefa & 2600 & Highland & 2 \\
21 & Abakara & Bale & 3000 & Highland & 2 \\
22 & Entoto & Shewa & 3000 & Highland & 2 \\
Total & & & & & $\mathbf{4 8}$ \\
\hline
\end{tabular}

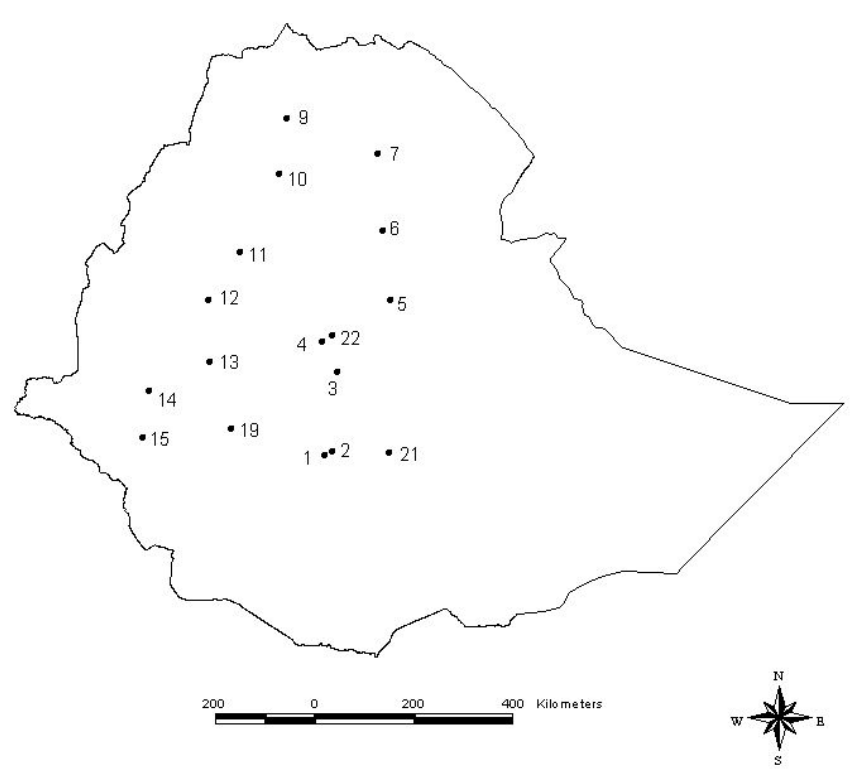

Figure 1. Geographical map of the 17 localities. The numbers refer to the different localities as described in Table 1.

length from tip to widest width $(r=0.92)$, indicating almost similar leaf shape throughout the material. Blade pubescence was also highly positively correlated with petiole pubescence $(r=0.97)$. Some other characters showed significant correlations but the association between the characters were low to moderate (either $0.33 \leq r \leq-0.30$ or $0.29 \leq r \leq 0.71$ ). Similarly, low but significant correlations were obtained only between average temperature and petiole length $(r=0.45)$, annual rainfall and filament length $(r=0.33)$, and annual rainfall and number of stamens $(r=-0.33)$. Therefore, most of the morphological characters used in the study appeared to be independent of temperature and rainfall.

\section{Analysis of variance (ANOVA)}

When hairiness was used as a categorical variable, petiole and inflorescence pubescence were the only characters that were found significant between hairiness groups. For altitude groups, ANOVA showed significant differences for 8 of the 16 characters studied (Table 4). Of these characters, a wider leaf apex, narrower sepals, and longer petioles were found in the lowland group than both the central highland and the highland groups. On average, leaves and petioles in most plants of the central highland are slightly pubescent while those of the lowland and the highland are almost glabrous. In endod, the presence of pubescent leaves has been found to reduce damage by larvae of the stem borer Gitona (Lugt, 1981). Therefore, it will be worthwhile to search for highly pubescent genotypes among the central-highland plants for use in endod breeding programs where resistance to insect larvae would be the basis for selection. 
Table 2. Summary of the 16 morphological characters scored from 48 herbarium specimens of endod collected in Ethiopia.

\begin{tabular}{|c|c|c|c|c|c|c|c|c|}
\hline Plant part & Characters & Acronym & \multicolumn{3}{|c|}{ Coding/measuring method } & Range & Mean & SD \\
\hline Leaf & 1. Length $(\mathrm{mm})$ & LEN & \multicolumn{3}{|c|}{ Representative median leaf } & $49.0-120.0$ & 84.29 & 15.48 \\
\hline “ & 2. Width $(\mathrm{mm})$ & WID & “ & “ & “ & $24.0-85.0$ & 46.79 & 12.81 \\
\hline “ & 3. Length from tip to widest width (mm) & LTW & “ & “ & “ & $31.0-77.0$ & 50.71 & 10.68 \\
\hline “ & 4. Petiole length $(\mathrm{mm})$ & PETL & “ & “ & “ & $9.0-31.0$ & 19.33 & 5.52 \\
\hline “ & 5. Leaf apex angle in degree & APEX & “ & “ & “ & $30.0-138.0$ & 72.02 & 23.94 \\
\hline “ & 6. Leaf base angle in degree & BASE & “ & “ & “ & $80.0-195.0$ & 122.81 & 26.95 \\
\hline Pubescence & 7. Leaf pubescence & BPUB $^{*}$ & \multicolumn{3}{|l|}{ All leaves } & $1.0-3.0$ & 1.56 & 0.74 \\
\hline “ & 8. Petiole pubescence & PETPUB ${ }^{*}$ & \multicolumn{3}{|c|}{ All petioles } & $1.0-3.0$ & 1.60 & 0.79 \\
\hline “ & 9. Inflorescence pubescence & INFPUB $^{*}$ & \multicolumn{3}{|c|}{ All inflorescences } & $1.0-3.0$ & 2.27 & 0.74 \\
\hline Inflorescence & 10. Inflorescence length $(\mathrm{mm})$ & INFL & \multicolumn{3}{|c|}{1 fully mature raceme } & $55.0-320.0$ & 150.8 & 57.4 \\
\hline “ & 11. No. of flowers within $3 \mathrm{~cm}$ INFL & FLNO & " $\quad$ " & “ & & $10.0-26.0$ & 18.38 & 3.69 \\
\hline Flower & 12. Flower pedicel length $(\mathrm{mm})$ & FLPEDL & “ & “ & & $3.0-11.0$ & 5.65 & 1.99 \\
\hline “ & 13. Filament length $(\mathrm{mm})$ & FILL & \multicolumn{3}{|c|}{ Average of 3 filaments } & $1.0-5.0$ & 2.60 & 1.08 \\
\hline “ & 14. Number of stamens & STNO & \multicolumn{3}{|c|}{ Average of 3 counts } & $10.0-19.0$ & 14.81 & 1.78 \\
\hline Sepal & 15. Sepal length $(\mathrm{mm})$ & SEPL & \multirow{2}{*}{\multicolumn{3}{|c|}{1 fully mature flower }} & $2.0-5.5$ & 3.56 & 0.74 \\
\hline$"$ & 16. Sepal width (mm) & SEPW & & & & $1.2-3.0$ & 1.98 & 0.40 \\
\hline
\end{tabular}

* 1 = glabrous; 2 = slightly pubescent; 3 = pubescent.

Table 3. Correlation coefficients between morphological characters, and between morphological characters and sampling site data (altitude, average temperature and annual rainfall). Character acronyms are as presented in Table 2.

\begin{tabular}{|c|c|c|c|c|c|c|c|c|c|c|c|c|c|c|c|c|}
\hline Character & LEN & WID & LTW & PETL & APEX & BASE & INFL & FLNO & BPUB & PETPL & INFPU & FLPEDI & SEPL & SEPY & FILL & STNO \\
\hline $\begin{array}{l}\text { WID } \\
\text { LTW }\end{array}$ & $\begin{array}{l}0.66^{*} \\
0.92^{*}\end{array}$ & $0.60^{*}$ & & & & & & & & & & & & & & \\
\hline PETL & $0.40^{*}$ & $0.49^{*}$ & $0.35^{\star}$ & & & & & & & & & & & & & \\
\hline APEX & 0.16 & $0.60^{*}$ & 0.02 & $0.33^{*}$ & & & & & & & & & & & & \\
\hline INFL & 0.13 & $0.45^{*}$ & 0.12 & $0.29^{*}$ & $0.36^{*}$ & 0.26 & & & & & & & & & & \\
\hline FLNO & -0.17 & 0.01 & -0.17 & -0.09 & 0.24 & 0.04 & -0.15 & & & & & & & & & \\
\hline BPUB & -0.13 & -0.07 & -0.10 & -0.09 & -0.11 & $0.30^{*}$ & -0.14 & 0.07 & & & & & & & & \\
\hline FLPEDL & 0.21 & 0.27 & 0.28 & -0.02 & -0.20 & 0.20 & 0.28 & -0.08 & 0.04 & 0.18 & 0.23 & & & & & \\
\hline SEPL & 0.11 & -0.04 & 0.09 & -0.21 & -0.28 & -0.03 & 0.00 & -0.26 & 0.23 & 0.25 & 0.02 & $0.50^{*}$ & & & & \\
\hline SEPW & 0.13 & -0.05 & 0.08 & -0.25 & $-0.30^{*}$ & -0.08 & -0.09 & -0.17 & 0.00 & 0.07 & -0.05 & $0.48^{*}$ & $0.71^{*}$ & & & \\
\hline FILL & 0.04 & 0.04 & 0.03 & 0.04 & 0.15 & 0.03 & 0.02 & -0.07 & 0.01 & -0.02 & -0.18 & 0.18 & 0.26 & 0.15 & & \\
\hline STNO & -0.02 & -0.08 & 0.02 & -0.28 & -0.23 & -0.04 & -0.01 & 0.06 & 0.08 & 0.14 & 0.06 & $0.41^{*}$ & 0.27 & 0.28 & 0.13 & \\
\hline
\end{tabular}

*Significant at $\mathrm{P}<0.05$; otherwise not significant.

\section{Cluster analysis}

Cluster analysis was performed using average taxonomic distance matrix (data not shown). The phenograms showed the separation of most samples into their respective hairiness (Figure 2a) and altitude (Figure 2b) groups. The glabrous plants were distinctly separated from the pubescent ones but the slightly pubescent plants appeared to be mixed both with glabrous and pubescent ones (Figure 2a). 
(a)

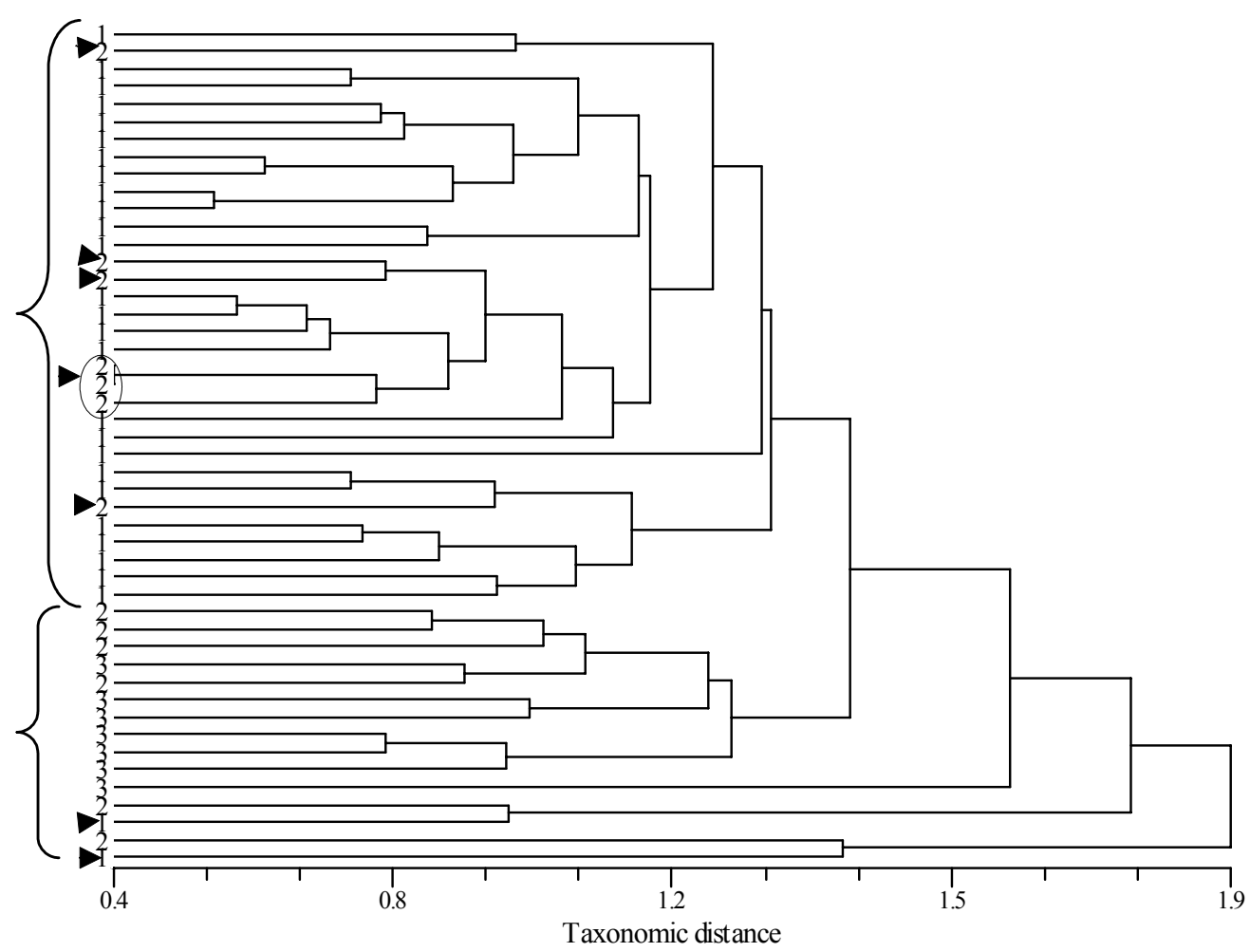

(b)

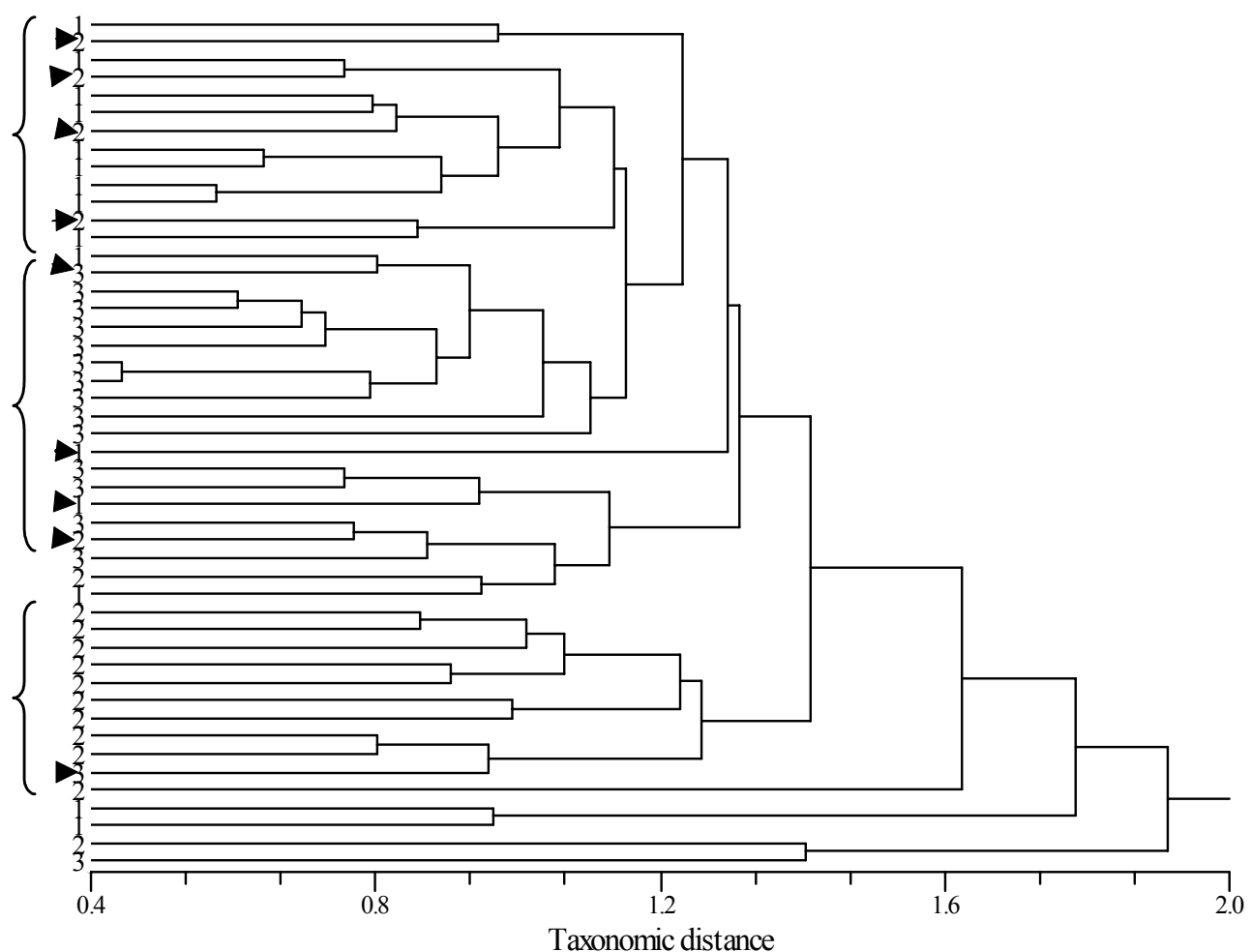

Figure 2. UPGMA phenograms depicting patterns of leaf hairiness and altitude groups. (a) Leaf hairiness groups (1= glabrous, mostly found within the upper bracket; 2=slightly pubescent, found both in the upper and lower brackets; 3=pubescent, mostly found within the lower bracket); (b) Altitude groups (1=lowland, mostly found in the upper bracket; $2=$ central highland, mostly found in the lower bracket; $3=$ highland, mostly found within the middle bracket). The arrows indicate incorrectly clustered samples. 
Table 4. Pair wise comparisons of 8 morphological characters between three altitude groups. Characters which were not significant among altitude groups at $p \leq 0.05$ in ANOVA were not considered for multiple comparison.

\begin{tabular}{lrrr}
\hline Characters & Lowland & $\begin{array}{c}\text { Central } \\
\text { highland }\end{array}$ & Highland \\
\hline Petiole length & $23.47 \mathrm{a}$ & $17.71 \mathrm{~b}^{*}$ & $17.19 \mathrm{~b}^{*}$ \\
Leaf apex & $89.67 \mathrm{a}$ & $63.06 \mathrm{~b}$ & $65.00 \mathrm{~b}$ \\
Leaf base & $122.0 \mathrm{ab}$ & $137.88 \mathrm{a}$ & $107.56 \mathrm{~b}$ \\
Inflorescence length & $178.50 \mathrm{a}$ & $154.4 \mathrm{ab}$ & $121.00 \mathrm{~b}$ \\
Leaf pubescence $^{* *}$ & $1.20 \mathrm{a}$ & $2.06 \mathrm{~b}$ & $1.38 \mathrm{a}$ \\
Petiole pubescence $^{* *}$ & $1.20 \mathrm{a}$ & $2.18 \mathrm{~b}$ & $1.38 \mathrm{a}$ \\
Inflorescence pubescence & $2.20 \mathrm{a}$ & $2.76 \mathrm{~b}$ & $1.81 \mathrm{a}$ \\
Sepal width $^{* *}$ & $1.73 \mathrm{a}$ & $2.09 \mathrm{~b}$ & $2.09 \mathrm{~b}$ \\
\hline
\end{tabular}

1 = glabrous; $2=$ slightly pubescent; 3 = pubescent

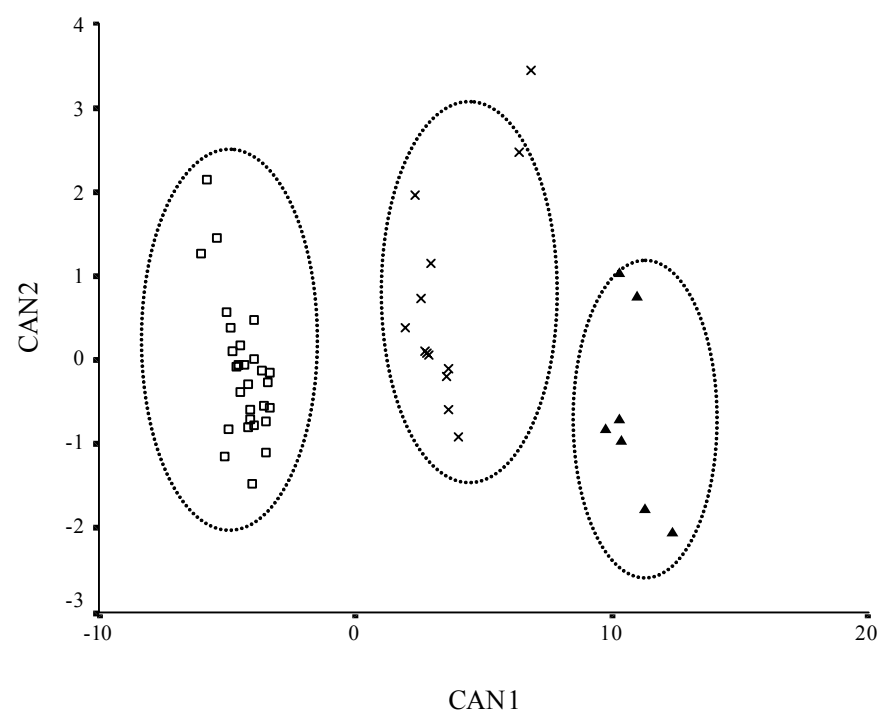

Figure 3. Plot of canonical discriminant functions (CAN) 1 and 2 for leaf hairiness groups based on 6 selected characters by the stepwise procedure: $\square=$ glabrous, $\mathrm{x}=$ slightly pubescent, and $\boldsymbol{\Delta}=$ pubescent.

\section{Discriminant analyses}

Leaf pubescence as a categorical variable: The stepwise procedure performed using hairiness as a classification variable identified 6 morphological characters (petiole pubescence, flower pedicel length, flower number, sepal length and width, inflorescence length) as the best differentiating characters (Table 5). A plot of Function 1 (99.4\%) and Function 2 (0.60\%) revealed the distinct separation of plants into their corresponding hairiness groups (Figure 3). CAN1 separated all the glabrous plants (group mean $=-4.34$ )

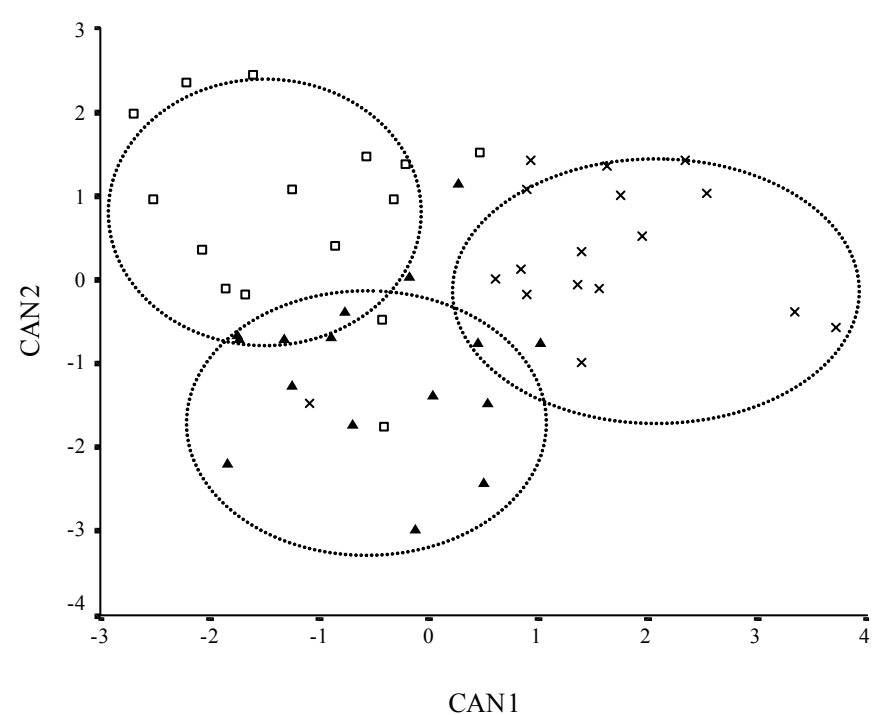

Figure 4. Plot of canonical discriminant functions (CAN) 1 and 2 for altitude groups based on 6 selected characters by the stepwise procedure: $\square=$ lowland, $\mathrm{x}=$ central highland, and $\boldsymbol{\Delta}=$ highland.

from the pubescent ones (group mean $=10.75$ ) with the slightly pubescent plants being intermediate between the former. Results of the canonical coefficients (Table 5) showed that the separation of hairiness groups by CAN1 is most strongly influenced by flower pedicel length ($0.78)$, sepal length (0.85), and petiole pubescence (1.37). $F$ statistics from pair wise comparisons of the 3 hairiness groups indicated significant differences between groups but the difference between glabrous and pubescent plants was much higher than the others (Table 6a). The correct classification of plants into their respective hairiness groups, based on the 6 selected morphological characters by the stepwise procedure, was $95.8 \%$ (Table $6 b)$. The data therefore strongly support the hypothesis that pubescent endod plants could be a separate taxon.

Altitude as a categorical variable: The discrimination model obtained with the stepwise procedure identified 6 morphological characters (leaf apex, leaf base, inflorescence pubescence, leaf length, leaf length from tip to widest width, and petiole length) as the best differentiating factors (Table 5). A plot of CAN1 (69.2\%) and CAN2 (30.8\%) showed the separation of most samples into their corresponding altitude groups as lowland, central-highland and highland (Figure 4). CAN1 separated the lowland plants (group mean $=-1.22$ ) from the central highland plants (group mean $=1.53$ ) with the highland plants positioned in between. CAN2 further separated the lowland plants (group mean $=0.83$ ) from the highlands (group mean $=-1.06$ ). As it is shown in Table 5, the separation of the altitude groups by CAN1 is most strongly influenced by leaf length from tip to widest width (-1.57), leaf apex (-1.05), and leaf length (1.38). The highest canonical coefficients for CAN2 were found 
Table 5. Summary of the morphological characters chosen by stepwise discriminant analysis for two categorical variables ( 3 altitude groups and 3 levels of leaf hairiness).

\begin{tabular}{|c|c|c|c|c|c|c|}
\hline \multirow{2}{*}{\multicolumn{2}{|c|}{ Categorical variable entered }} & \multicolumn{3}{|c|}{$\begin{array}{l}\text { Stepwise discriminant analysis } \\
\text { summary }\end{array}$} & \multicolumn{2}{|c|}{$\begin{array}{l}\text { Standardized canonical } \\
\text { function coefficients }\end{array}$} \\
\hline & & F statistics & Prob > F & Wilks' Lambda & CAN1 & CAN2 \\
\hline \multirow{6}{*}{ Altitude groups } & 1. Petiole length & 8.54 & $<0.001$ & 0.52 & -0.29 & 0.77 \\
\hline & 2. Inflorescence pubescence & 7.46 & $<0.001$ & 0.43 & 0.69 & 0.33 \\
\hline & 3. Leaf apex & 7.02 & $<0.001$ & 0.36 & -1.05 & 0.32 \\
\hline & 4. Leaf base & 6.72 & $<0.001$ & 0.30 & 0.87 & 0.32 \\
\hline & 5. Leaf length from tip to widest width & 7.10 & $<0.001$ & 0.29 & -1.57 & 0.24 \\
\hline & 6. Leaf length & 6.76 & $<0.001$ & 0.25 & 1.38 & -0.85 \\
\hline \multirow{6}{*}{ Leaf hairiness } & 1. Petiole pubescence & 369.44 & $<0.001$ & 0.06 & 1.37 & 0.03 \\
\hline & 2. Flower pedicel length & 87.86 & $<0.001$ & 0.04 & -0.78 & 0.30 \\
\hline & 3. Flower number & 61.78 & $<0.001$ & 0.04 & 0.32 & -0.66 \\
\hline & 4. Sepal length & 50.01 & $<0.001$ & 0.03 & 0.85 & -0.16 \\
\hline & 5. Sepal width & 41.45 & $<0.001$ & 0.03 & -0.59 & 0.33 \\
\hline & 6. Inflorescence length & 36.18 & $<0.001$ & 0.02 & -0.32 & 0.50 \\
\hline
\end{tabular}

Table 6. Discriminant analyses, based on 6 morphological characters selected by the stepwise procedure, among 3 levels of leaf hairiness.

a. Pair wise comparisons of the three levels of leaf hairiness; each $\mathrm{F}$ statistics has 6 and 40 degrees of freedom.

\begin{tabular}{llll}
\hline & Glabrous & Slightly pubescent & Pubescent \\
\hline $\begin{array}{l}\text { Glabrous } \\
\text { Slightly pubescent }\end{array}$ & $\mathrm{F}=82.62, \mathrm{p}<0.001$ & \\
Pubescent & $\mathrm{F}=189.11 ; \mathrm{p}<0.001$ & $\mathrm{~F}=36.14 ; \mathrm{p}<0.001$ & \\
\hline
\end{tabular}

b. Cross-validated classification results for the three levels of leaf hairiness.

\begin{tabular}{|l|c|c|c|c|}
\hline Actual group & $\mathrm{N}$ & \multicolumn{3}{|c|}{ Predicted group } \\
\cline { 3 - 5 } & & Glabrous & Slightly pubescent & Pubescent \\
\hline Glabrous & 28 & 28 & 0 & 0 \\
Slightly pubescent & 13 & 0 & 11 & 2 \\
Pubescent & 7 & 0 & 0 & 7 \\
\hline 46 plants (95.80\%) were correctly classified.
\end{tabular}

Table 7. Discriminant analyses, based on 6 morphological characters selected by the stepwise procedure, among 3 altitude groups of endod sampled from 17 localities.

a. Pair wise comparisons of altitude groups; each $F$ statistics has 6 and 40 degrees of freedom.

\begin{tabular}{llll}
\hline & Lowland & Central highland & Highland \\
\hline Lowland & & \\
Central highland & $F=9.27, p<0.001$ & \\
Highland & $F=4.68 ; p<0.001$ & $F=7.08 ; p<0.001$ & \\
\hline
\end{tabular}

b. Cross-validated classification results for altitude groups.

\begin{tabular}{|l|c|c|c|c|}
\hline Actual group & \multirow{N}{*}{} & \multicolumn{3}{|c|}{ Predicted group } \\
\cline { 3 - 5 } & & Lowland & Central highland & Highland \\
\hline Lowland & 15 & 10 & 1 & 4 \\
Central highland & 17 & 0 & 16 & 1 \\
Highland & 16 & 5 & 3 & 8 \\
\hline 34 plants (70.80\%) were correctly classified.
\end{tabular}


for leaf length (-0.85) and petiole length (0.77). F statistics from pairwise comparisons of the 3 altitude groups have revealed significant differences between groups (Table 7a). The $\mathrm{F}$ values were, however, much lower than values earlier reported (Semagn et al., 2000) using random polymorphic DNA analysis (RAPD) data. Similarly, the correct classification of plants into their respective altitude groups, based on the 6 selected morphological characters by the stepwise procedure, was $70.8 \%$ (Table $7 \mathrm{~b}$ ), which is much lower than the $92.8 \%$ correct classification we previously reported (Semagn et al., 2000). The present data therefore did not support the presence of morphological ecotypes along altitudinal gradients.

\section{ACKNOWLEDGMENTS}

We acknowledged the Norwegian Universities Committee for Development Research and Education (NUFU) for financial support. We would also like to thank Prof. Inger Nordal and Mr. Thomas Marcussen of the University of Oslo (Norway) for their valuable suggestions on the draft manuscript.

\section{REFERENCES}

Abate D, Fesseha S (1994). In vitro and in vivo antifungal activity of endod (Phytolacca dodecandra). In: Gemetchu T, Birrie H, WoldeYohannes L, Gundersen SG (eds.) Present status and future trends of research on endod and schistosomiasis in Ethiopia. Proceedings of a preparatory workshop held in Nazareth, Addis Ababa University Press, pp. 62-66.

Adams RP, Neisess KR, Parkhurst RM, Makhubu LP,Wolde-Yohannes L (1989). Phytolacca dodecandra (Phytolaccaceae) in Africa. Taxon 38: $17-26$.

Auquier P, Renard R (1975). Nombres chromosomiques de quelques Angiospermes du Rwanda, Burundi et Kivu (Zaire). Bull. Jard. Bot. Nat. Belg. 45: 421-445.

Dalziel JH (1936). The useful plants of West Africa. Crown Agents, London.

Kloos H, McCullough FS (1983). Review of plants with recognized molluscicidal activity. Proceedings on Plant Molluscicides of the Scientific Working Group on Schistosomiasis. Geneva, Switzerland.

Lambert JDH, Temmink JHM, Marquis J, Parkhurst RM, Lugt CB, Schoonen AJM, Holtze K, Warner JE, Dixon G, Wolde-Yohannes L, Desavigny D (1991). Endod: Safety evaluation of a plant molluscicide. Regul. Toxicol. Pharmacol. 14: 189-201.

Lemma A (1965). A preliminary report on the molluscicidal properties of Phytolacca dodecandra. Ethiop. Med. J. 3: 187-190.

Lemma A (1970). Laboratory and field evaluation of the molluscicidal property of Phytolacca dodecandra. Bull. W. H. O. 42: 597-617.

Lemma A, Wolde-Yohannes L, Praleigh PC, Klerks PL, Lee HH (1991). Endod is lethal to Zebra Mussels and inhibit their attachment. J. Shellfish Res. 10:361-365.

Lugt CB (1981). Phytolacca dodecandra berries as means of controlling bilharzia-transmitting snails. Litho Printer, Addis Ababa, 61 pp.

Mishra MK (1997). Stomatal characteristic at different ploidy levels in Coffea L. Ann. Bot. 80: 689-692.

Molgaard $P$, Chihaka A, Lemmich E, Furu P, Windberg C, Ingerslev F, Halling-Sorensen B (2000). Biodegradability of molluscicidal saponins of Phytolacca dodecandra. Regul. Toxicol. Pharmacol. 32:248-255.
Parkhurst RM, Thomas DW, Skinner WA, Cary LW (1974). Molluscicidal saponins of Phytolacca dodecandra: Lemmatoxin. Can. J. Chem. 52:702-705.

Polhill RM (1971). Phytolaccaceae. In: Polhill RM (ed) Flora of Tropical East Africa. Royal Botanical Garden, Kew, pp. 1-8.

Rohlf FJ (1998). NTSYSpc, Numerical Taxonomy and Multivariate Analysis System. Version 2.0, Exeter software, New York.

Santen EV, Casler EV (1986). Evaluation of indirect ploidy indicators in Dactylis C. Subspecies. Crop Sci. 26: 848-852.

Semagn K, Bjornstad A, Stedje B, Bekele E (2000). Comparison of multivariate methods for the analysis of genetic resources and adaptation in Phytolacca dodecandra using RAPD. Theor. Appl. Genet. 101:1145-1154.

Semagn K, Stedje B, Bjornstad A (2001). Analysis of genetic diversity and structure in Ethiopian populations of Phytolacca dodecandra using RAPDs. Hereditas 135:51-60.

Speckman G, Post JJJ, Dijkstra H (1965). The length of stomata as an indicator of polyploidy in rye grass. Euphytica 14: 225-230.

Spielman A, Lemma A (1973). Endod extract. A plant derived molluscicide: Toxicity for mosquitoes. Am. J. Trop. Med. Hyg. 22:802

Stolzenberg SJ, Parkhurst RM (1976). Blastocidal and contraceptive actions by an extract and compounds from endod (Phytolacca dodecandra). Contraception 14:39-51.

Tan GY, Dunn GM (1973). Relationship of stomatal length and frequency and pollen grain diameter to ploidy level in Bromus inermis leyss. Crop Sci. 13: 322-334.

Wolde-Yohannes $L$ (1983). Past and ongoing agrobotanical studies of Phytolacca dodecandra (Endod) in Ethiopia. In: Lemma A, Heyneman D, Silangwa SM (eds.) Phytolacca dodecandra (Endod). Final Report of the international workshop, Lusaka, Zambia, March 1983, pp.125-129. 